\title{
A CONSTRUÇÃO DA IDENTIDADE DO PEDAGOGO: UM PROCESSO QUE COMEÇA ANTES DO OFÍCIO
}

\section{ARTIGO DE REVISÃO}

RODRIGUES, Thaynan de Oliveira Soares ${ }^{1}$

FERREIRA, Valéria Maria Fusch ${ }^{2}$

RODRIGUES, Thaynan de Oliveira Soares. FERREIRA, Valéria Maria Fusch. A construção da identidade do pedagogo: Um processo que começa antes do ofício. Revista Científica Multidisciplinar Núcleo do Conhecimento. Ano 05, Ed. 08, Vol. 12, pp. 144-158. Agosto de 2020. ISSN: 2448-0959, Link de acesso: https://www.nucleodoconhecimento.com.br/pedagogia/identidade-dopedagogo

\section{RESUMO}

A concepção da docência tem se transformado ao longo dos anos devido as mudanças e desenvolvimento da sociedade em seus aspectos culturais, políticos e econômicos. Dessa forma, a função "ser professor" tem assumido novas concepções e exigências profissionais em sua atuação. Diante disso, permanece a problemática da construção da identidade profissional docente, especificamente nos cursos de Pedagogia, os quais visam preparar 0 pedagogo profissional mediante 0

\footnotetext{
${ }^{1}$ Graduada em Pedagogia pelo Centro Universitário Salesiano de São Paulo - Unisal (2019). Pós-graduando Neurociências, Educação e Práticas Pedagógicas pelo Unisal. 2 Orientadora. Possui graduação em Fonoaudiologia pela UNIMEP (1997) e licenciatura em Pedagogia pelo Centro Universitário Claretiano (2015), Aprimoramento em Linguagem, Aprendizagem e Neurociência pelo CEFAC/SP (2006). Especialista em Psicopedagogia Construtivista pela Universidade Estadual de Campinas - UNICAMP (2013). Mestra em Educação pela Faculdade de Educação da Universidade Estadual de Campinas - UNICAMP (2018).
} 
desenvolvimento de competências e habilidades específicas para sua atuação. Entretanto, nota-se que os processos de construção da identidade do pedagogo não se restringem apenas à dimensão acadêmica, mas em um processo que antecede ao ingresso no ensino superior. Dessa forma, o presente artigo tem como objetivos especificar acerca dos aspectos e processos que constroem a identidade do professor pedagogo. Além disso, refletir sobre as escolhas de discentes de Pedagogia ao ingressar para o curso e a respeito do processo de formação da identidade profissional na trajetória acadêmica. Como metodologia do trabalho optou-se pela revisão bibliográfica no período de 2009 a 2019, em livros físicos da área e na busca por estudos acerca da temática no Google Acadêmico e na base de dados da Capes. O artigo discorre também, acerca de uma pesquisa de campo envolvendo discentes do $8^{\circ}$ semestre de um curso de Pedagogia em uma instituição de ensino particular, as quais refletem sobre suas experiências que sucederam a escolha do referido curso e as competências adquiridas ao longo de sua trajetória acadêmica.

Palavras-chave: Formação docente, identidade profissional, pedagogia.

\section{INTRODUÇÃO}

A questão da construção da identidade do professor é um tema discutido e investigado por muitos estudiosos. O "ser professor" implica em diversas concepções históricas que, em princípio, baseiam-se no desenvolvimento de competências e habilidades em sua atuação profissional. Tais competências e habilidades se manifestam no processo de formação do professor, enquanto discente na graduação, e permeia ao longo de sua carreira por meio de suas experiências e práticas pedagógicas desenvolvidas, além de uma formação continuada.

O professor é um sujeito histórico e social e o principal atributo de seu ofício é o de ensinar seus alunos. Dessa forma, conforme artigo 4 do Conselho Nacional de Educação pela Resolução[3] CNE/CP ㄲo1/2006, o curso de licenciatura em Pedagogia, em princípio, visa preparar os futuros pedagogos para exercer o magistério na Educação Infantil e no primeiro ciclo do Ensino Fundamental ( $1^{\circ}$ ao $5^{\circ}$ ano). Entretanto, o curso contribui para a formação de seus discentes para atuarem 
também em contextos de educação informal, gestão e administração de escolas e em demais contextos que se faz necessário a atuação do pedagogo.

Independentemente da atuação do pedagogo no âmbito educacional, é de suma importância que este esteja preparado profissionalmente e desenvolva as habilidades e saberes técnicos adquiridos ao longo de sua formação universitária. Dessa forma, o pedagogo precisa estar pronto para progredir em sua prática pedagógica e saber lidar com profissionalismo no contexto o qual está exercendo seu ofício. Todavia, este artigo remete exclusivamente a atuação do professor pedagogo no contexto escolar e a respeito do processo de construção de sua identidade profissional.

Muitos estudiosos afirmam que a construção da identidade do professor é um processo contínuo que acontece em toda a trajetória de sua carreira no magistério. Isso significa que a identidade profissional do professor pode se transformar na medida em que constrói seus conhecimentos e práticas pedagógicas por meio de suas experiências acadêmicas e sociais. No entanto, no momento de sua atuação, o profissionalismo do professor deve ser preciso e formidável, ou seja, faz-se necessário comprometimento com seu ofício, construção coletiva do trabalho pedagógico, dedicação ao desenvolver suas aulas, domínio do conteúdo, maturidade intelectual, autodomínio, respeito à condição social do aluno e compromisso em cumprir todas as suas responsabilidades enquanto professor.

Dessa forma, "a expectativa institucional em relação aos professores é que eles cheguem prontos para o cumprimento de sua tarefa, ou seja, que se revelem aptos a dar conta do ritual da sala de aula e que implementem adequadamente o ofício que aprenderam" (FONTANA, 2005, p. 148). Dessa forma, o pedagogo torna-se professor tanto pela reprodução de competências definidas pelo projeto histórico de escolarização quanto pela representação de concepções profissionais já estabelecidas pela sociedade.

Contudo, além dessa qualificação e profissionalismo exigido no âmbito da docência, a construção da identidade do professor pedagogo se destina para dimensões que abrangem valores, ações, comportamentos, memórias, experiências e decisões que 
o levaram a escolha de seu ofício. Logo, o "ser professor" se aplica ao progresso de dimensões profissionais e pessoais, teóricas e metodológicas que constroem a profissão docente, muitas vezes, rompendo com o estabelecido (BRAGANÇA, 2012). Dessa forma, a formação do professor passa a ser vista de forma individual e coletiva: inicia antes mesmo do ingresso no ensino superior e se prolonga por toda a sua vida, sempre ligada a instituição escolar e a sociedade como um todo.

\section{AS DIMENSÕES QUE CONTRIBUEM PARA A CONSTRUÇÃO DA IDENTIDADE DO PROFESSOR PEDAGOGO}

A profissão de educador consiste, além de uma ação docente, uma prática social. Dessa forma, o educador intercede na realidade social por meio da educação, sobretudo nas instituições de ensino. Entretanto, para que o educador possa desenvolver essa prática, faz-se necessário um preparo e um desempenho que se adeque às exigências do ensino. Dessa forma, além do educador ter os conhecimentos a respeito da realidade social que está inserido, os quais se converterão no conteúdo do ensino, deve-se "aliar-se ao domínio de recursos teóricos e metodológicos para transmissão, partilha e socialização dos conhecimentos. Além disso, é preciso uma visão crítica dos princípios que fundamentam sua prática, dos objetivos, dos compromissos por ela requeridos." (RIOS, 2002 apud PIMENTA e LIMA, 2012, p. 66).

A visão crítica dos princípios que fundamentam a prática do professor remete-se principalmente ao próprio educador. Trata-se de analisar sua posição em sala de aula, a maneira como lida com as objeções inusitadas, a forma como aplica o conteúdo, as atitudes e trabalhos desenvolvidos, enfim, tudo o que pressupõe a sua prática docente. Dessa forma, a prática docente implica no desenvolvimento da identidade profissional do professor ao longo de sua carreira.

Segundo Marcelo (2010), a identidade do professor não surge automaticamente após a conclusão da licenciatura, é preciso construí-la e modelá-la. E isso é um processo individual e coletivo, complexo e dinâmico. O autor ainda alega que existe uma diversidade de identidades docentes em que a subjetividade de cada uma delas 
depende do local o qual está inserida e dos fatores que contribuem para essa formação. Dessa forma, a relação com os colegas de trabalho é de suma importância para a construção da identidade docente.

As identidades docentes podem ser entendidas como um conjunto heterogêneo de representações profissionais e como um modo de resposta à diferenciação ou identificação com outros grupos profissionais. Existem identidades múltiplas que dependem dos contextos de trabalho ou pessoais e das trajetórias particulares de vida profissional. A identidade profissional docente se apresenta, pois, com uma dimensão comum a todos os docentes, e com uma dimensão específica, em parte individual e em parte ligada aos diversos contextos de trabalho. Trata-se de uma construção individual referida à história do docente e às suas características sociais, mas também de uma construção coletiva derivada do contexto no qual o docente se desenvolve. (MARCELO, 2010, p 19).

Além da relação coletiva no ambiente educacional o qual o pedagogo está inserido, as competências são fundamentais para a construção da identidade do professor. Elas, segundo Pimenta e Lima (2012), significam teoria e prática para fazer algo, o conhecimento em situação, o que é fundamental para o professor. Dessa forma, ter competência,

é diferente de ter conhecimento e informação sobre o trabalho, sobre aquilo que se faz; é ter visão de totalidade, consciência ampla das raízes, dos desdobramentos e implicações do que se faz para além da situação em que se está, das origens, dos porquês e finalidades. (PIMENTA e LIMA, 2012, p. 86).

Para Altet, Charlier et al (2001), o termo competência é amplo e compreende as aquisições dos saberes: saber-fazer, saber-ser, saber-tornar-se. Elas são necessárias para a realização da prática pedagógica, atribuindo, assim, a resolução de problemas em um domínio determinado. Essas aquisições são desenvolvidas no ambiente acadêmico e/ou escolar, por meio dos encontros com professores, colegas e alunos formadores. Dessa forma, o professor

não somente aprende os conteúdos e as condutas úteis a um melhor domínio de seu trabalho, como também de si mesmo, de todo modo, dentro e quanto a seu trabalho. Entra assim nessa dinâmica que o identifica e com qual se identifica, ao invés de ser "como um conjunto de 
competências", como "uma pessoa em relação e em processo de construção para o futuro". Procedendo assim, ele estará desenvolvendo o essencial das competências que definem o profissional. (ALTET, CHARLIER et al, 2001, p. 44).

Até aqui, compreende-se que a construção da identidade do professor pedagogo aplica-se ao relacionamento coletivo e dinâmico e ao desenvolvimento de competências adquiridas ao longo de seu percurso acadêmico e escolar. No entanto, há outros fatores que contribuem para que essa construção inicie antes mesmo do ingresso do professor pedagogo no âmbito escolar. Trata-se das dimensões sociais.

Segundo o site Conceito.De dimensão, do latim dimenšo, é um aspecto ou uma singularidade de algo. Todavia, a palavra dimensão tem diversos usos de acordo com o contexto utilizado. Dessa forma, pode se tratar de uma característica, de uma extensão, de uma circunstância ou de uma fase de algo.

Tratando-se das dimensões que compõe o processo de formação e construção da identidade do professor pedagogo, o conceito aqui atribuído de dimensão passa a ser as fases históricas, sociais, culturais, políticas que o professor pedagogo passa por sua vida, as quais não constrói apenas sua identidade profissional, mas sobretudo, sua identidade pessoal.

Em sua obra Histórias de vida e formação de professores: diálogos entre Brasil e Portugal (2012), a doutora Inês Bragança reúne informações sobre a trajetória da vida acadêmica de algumas professoras do primeiro ciclo da Educação Básica e destaca que as dimensões mais importantes para a vida e formação docente implicam em um movimento baseado na formação acadêmica institucional, na história familiar e pessoal/ de vida, opções e trajetórias religiosas e a memória escolar (BRAGANÇA, 2012). Tais dimensões contribuem de forma direta ou indireta na formação do professor e manifestam-se em diferentes formas na vida e no progresso de cada um.

A dimensão da formação acadêmica institucional, em princípio, implica o ingresso no Ensino Superior. Contudo, Bragança (2012, p. 210) afirma que essa formação institucional se refere a três etapas: 
a pré-formação, que compreende a escolarização formal e experiências anteriores à formação profissional, especificamente voltadas para a docência; a formação inicial, destinada a preparação profissional que habilita e assegura o exercício da docência; e a formação contínua, por meio de iniciativas formais que visam à continuidade dos processos de estudo e de aperfeiçoamento profissional. (BRAGANÇA, 2012, p. 210).

A pré-formação, nesse caso, se dá mediante a conclusão do ensino médio, pois é o momento em que o aluno decide desenvolver sua profissão com base em pesquisa do ofício desejado ou influências sociais. Todavia, a escolha do magistério pode advir de experiências profissionais que compreende o âmbito da educação. Dessa forma, a formação acadêmica já se inicia antes mesmo da entrada na graduação, pois a escolha do curso se deu a partir de experiências práticas ou não.

$\mathrm{Na}$ graduação, o futuro professor pedagogo se depara com aprendizagens inerentes de diferentes disciplinas, conhecimentos técnicos e científicos, experiências e vivências coletivas, pesquisa e experimentação de práticas pedagógicas. Além disso, os componentes curriculares do curso como o Estágio Supervisionado e Atividades Complementares são de suma importância para a formação prática, pois permitem aos discentes desenvolver habilidades e competências do ofício mediante a orientação de profissionais experientes.

A formação contínua se aplica ao interesse do professor em buscar novos saberes que visam o aperfeiçoamento profissional. Trata-se de cursos de pós-graduação cujo objetivo é qualificar profissionais em áreas específicas e desenvolver neles o perfil de professor pesquisador. A escolha para uma formação continuada dependerá da iniciativa do professor e do interesse na área que deseja se aperfeiçoar para dar continuidade em sua carreira.

Desse modo, a dimensão da formação acadêmica institucional desenvolve no professor pedagogo competências e habilidades específicas, o saber analisar, refletir e justificar por meio de suas interações com o professor e seus colegas, além de ajudar na construção do pensamento crítico. Entretanto, conforme alega Altet, Charlier et al (2001), a formação acadêmica inicial é considerada por muitos como 
demasiadamente teórica, não suficientemente prática ou demasiadamente ligada a modelos.

Os professores queixam-se que seus formadores 'não explicaram o suficiente' sobre as dificuldades que seriam encontradas, nem da influência dos problemas sociais sobre a classe; que não 'forneceram informações suficientes' sobre a psicologia do aluno, as técnicas, etc. (ALTET, CHARILER et al, 2001, p. 47).

Diante dessa premissa, é possível explicitar a insegurança e falta de preparo dos professores recém-formados ao ingressar na sala de aula. De fato, o percurso na graduação baseia-se profundamente na teoria, mas propõe, na medida do possível, atividades práticas para a construção do conhecimento e da experiência docente. Dessa forma, a prática deve articular-se de forma integrada com a teoria, todavia, é manifestada em diferente situações e contextos. E é nesse momento que o professor terá a oportunidade de desencadear novas competências e habilidades para a resolução de seus problemas no ofício. Porém, a dimensão da formação acadêmica institucional ainda não é suficientemente para a construção integral da identidade do professor pedagogo.

$\mathrm{Na}$ dimensão da história familiar e pessoal/de vida, Bragança (2012) cita a teoria tripolar da formação humana proposta por Pineau que envolve a auto, hétero e ecoformação. A autoformação é uma dimensão pessoal que implica a reflexão das questões cotidianas que levam o indivíduo a problematizar o passado e a construir projetos sobre o futuro; a heteroformação apresenta a presença de outros sujeitos que permeiam a história de vida do indivíduo, ou seja, pessoas com que este aprende e ensina; e, finalmente, a ecoformação articula a relação do indivíduo com o mundo, o trabalho e a cultura. (PINEAU, 1988 apud BRAGANÇA, 2012).

Dessa forma, a dimensão da história familiar e pessoal/ de vida baseia-se principalmente no conceito de dimensão pessoal e coletiva em que o professor atribui a responsabilidade por seu processo de formação, ou seja, ele assume a posição do indivíduo que se autoeduca por meio de suas experiências pessoais e coletivas. 
Se entendermos a formação como um processo interior, referido à possibilidade de o sujeito se permitir tocar pelos movimentos educativos da vida, transformando-os em experiências significativas, reconhecemos, então, o lugar central do sujeito. Afirmamos, no entanto, que a intensidade das experiências que se tornam significativas e formativas é necessariamente coletiva. Elas vêm de um investimento social, no caso, do processo escolar, ou das tramas, dos encontros e desencontros que temos com os outros e com o meio, ao longo da vida. (BRAGANÇA, 2012, p. 66).

Nesse sentido, essas dimensões que contribuem para construção da identidade do professor pedagogo apresentam movimentos de aprendizagens experienciais, pois estas articulam o conhecimento, as práticas, as técnicas e os valores atribuídos por meio da relação com o eu e a relação com o outro. Dessa forma, a formação fundamentada nessas aprendizagens, não se baseia no acúmulo de saberes e competências, mas na experiência imprescindível do professor que se transforma, reputando assim, novas formas de ser e estar no mundo.

Nessa perspectiva de análise, formação e processo identitário se encontram e se constituem um campo de interseção na transformação do sujeito, mas se distinguem, sendo a primeira, processo de conhecimento vital em movimento e a segunda, o reflexo provisório desse processo. A identidade, assim, afirma-se como a imagem refletida no espelho vista pelo próprio sujeito e pelos outros; e a formação, como que se processa internamente e permite a configuração provisória que se reflete (BRAGANÇA, 2012, p. 113).

No âmbito da docência, a instituição escolar é um espaço imprescindível para a construção da identidade do professor pedagogo, pois é um ambiente que, além dele poder expor suas práticas e aprendizagens pedagógicas, partilha a construção de uma prática educativa coletiva com seus colegas educadores e alunos. Aliás, estes são alguns dos principais sujeitos formadores nesse processo. Por lei[4], as instituições de Ensino Superior aderem ao Estágio Supervisionado durante a graduação para que os discentes já possam ter esse contato com a escola. Essa interação com o ambiente escolar proporciona ao futuro pedagogo novas aprendizagens e competências na medida em que se interessa e empenha-se nesse processo. 
Bragança (2012) ainda relata sobre a dimensão da opção ou trajetória religiosa. Muitos educadores defendem a ideia de que o ensino deve ser laico, sem a interferência de qualquer religião. Dessa forma, um professor maduro intelectualmente concorda que a sala de aula deve ser um ambiente livre de qualquer dogma religioso, a menos que a escola preza por alguma religião específica. Porém, ao falar sobre essa dimensão, a autora pressupõe a trajetória religiosa do professor como um sujeito no mundo em que suas crenças constroem o eu. A religião é uma instituição social e, assim como as demais instituições sociais presentes na sociedade, ela desenvolve no indivíduo valores, atitudes e comportamentos que o transformam. Desse modo, tais valores manifestam-se na personalidade do indivíduo e reflete, direta ou indiretamente, suas ações na sociedade. Independentemente da escolha religiosa do professor pedagogo ou mesmo a descrença em tal, contribui para a formação da sua identidade uma vez que instaura princípios morais no eu.

Por fim, outra dimensão que Bragança (2012) discorre é a respeito da dimensão da memória escolar. Com base na trajetória de vida das professoras que entrevistou, a autora pode compreender que as experiências e memórias escolar das professoras, enquanto discentes da Educação Básica, instauraram nelas o desejo pela docência. Nesse processo, a referência de bons ou "maus" professores, o laço afetivo com colegas e família, as condições sociais e políticas, tornaram-se referências para a busca pelo magistério. Gonçalves (2010, p. 80) também confirma essa premissa em sua dissertação:

Compreendemos que a formação dos professores ocorre em processo constante que se inicia desde a formação escolar elementar quando o indivíduo está em contato com seu primeiro professor ou professora, formando na vivência as primeiras ideias ou o conceito inicial da profissão docente. (GONÇALVES et al, 2010, p. 80).

Isso significa que, antes mesmo de ingressarem no Ensino Superior, os professores já trazem para a formação de sua identidade profissional conceitos, princípios e valores que foram instituídos por meio do contexto e das relações coletivas que mantiveram durante seu percurso escolar da Educação Básica. Essas experiências e 
valores adquiridos nesse percurso serão desenvolvidos e partilhados ao longo da graduação.

Gonçalves et al. (2010) também relata sobre a memória escolar das professoras enquanto docentes da Educação Básica. Dessa forma, conclui que há escolas, contextos e alunos diferentes, portanto, a experiência profissional do professor pedagogo nunca será a mesma de seus colegas ou a mesma em todas as instituições que lecionar. O professor se deparará com a frustração de algum aluno não compreender o conteúdo que ensina, com a falta de recursos para suas aulas, com professores exaustos e sem esperança na educação, mas também irá reinventar, aprenderá com seus colegas de trabalho e com seus alunos e isso contribuirá ao longo de sua carreira a formação de sua identidade.

Dessa forma, para a construção da identidade do professor pedagogo, o desenvolvimento de competências e as dimensões sociais, que permeiam a sua trajetória profissional e de vida são fundamentais, pois despertam nele o desejo de aprimorar sua prática pedagógica e buscar sempre pelo conhecimento. Assim, o professor pedagogo tornará um profissional reflexivo sobre suas ações na realidade social que está inserido e será capaz de buscar sempre a inovação em prol do desenvolvimento de seus alunos, mas, sobretudo, em prol do seu próprio desenvolvimento.

\section{POR QUE A PEDAGOGIA? REFLEXÕES DAS REPRESENTAÇÕES SOCIAIS DE DISCENTES}

A formação inicial do professor pedagogo é um conjunto de informações, estratégias e métodos que unificam as aprendizagens e experiências vividas por ele anteriormente, transformando, assim, progressivamente o seu trajeto acadêmico. Assim sendo, a graduação é o momento em que o discente adquire o conhecimento do que é preciso fazer e como fazer. Dessa forma, a graduação insere-se na vida do futuro professor pedagogo como um recurso às experiências já vivenciadas, o conhecimento profundo dos métodos de ensino, a imersão no ofício e os estágios para aprimoramento e observação da prática pedagógica. 
Por conseguinte, a formação inicial é uma construção pessoal e coletiva que se fundamenta em ações práticas cotidianas em sala de aula e reflexões dessas ações por meio da orientação do professor formador, cuja missão é participar como um mediador que facilita a construção do conhecimento em uma estratégia de coformação. (ALTET, CHARLIER, 2001). Isso significa que a formação do professor pedagogo implica o desenvolvimento de competências a serem adquiridas durante a graduação por meio das disciplinas, projetos, interações, dos Estágio Supervisionados, mas sobretudo, a necessidade de se autoavaliar e de questionar constantemente as ações para compreender seu ofício.

Baseando-se na visão de Bragança (2012) sobre as dimensões formadoras que contribuem para a construção da identidade profissional do professor pedagogo, foi realizada uma pesquisa qualitativa com discentes do $8^{\circ}$ semestre do curso de licenciatura em Pedagogia, em uma instituição de cunho privado. A pesquisa ocorreu por meio de um questionário com quatro perguntas a serem respondidas de forma dissertativa.

A pesquisa contou com a participação de 31 discentes, sendo a maioria na faixa etária de 20 a 25 anos. A primeira pergunta do questionário diz respeito a motivação ou influência que as discentes tiveram para a escolha do curso. A maioria alegou escolher o curso pela admiração de professoras que já tiveram. Muitas delas afirmaram que o interesse surgiu a partir do momento em que entraram em escolas para trabalharem como monitoras. Outras, alegaram escolher o curso de Pedagogia devido a influência de parentescos que já trabalhavam na área. Apenas uma aluna alegou escolher o curso pelo custo ser mais acessível, mas afirmou que posteriormente gostou muito, cogitando uma formação continuada na área.

Acredito que minha trajetória escolar e os professores que fizeram parte dela foram os principais influenciadores. Além disso, eu sempre gostei muito de ensinar as pessoas e assim ajudá-los. Minha mãe e alguns professores foram fundamentais na minha escolha. (DISCENTE 7, ago 2019).

Eu tinha muitas dúvidas quanto minha escolha e curso após terminar o Ensino Médio, então comecei a pesquisar cursos e identificar 
características dos mesmos que combinava comigo. Pelo jeito extrovertido, brincalhão e também muito observador, conclui que a Pedagogia era o curso que mais tinha a ver comigo. Ainda não tinha certeza quando escolhi, mas o que me motivou foram as características do curso que se encaixavam com os meus gostos. (DISCENTE 12, ago 2019).

O meu desejo sempre foi esse, desde os doze anos. No Ensino Médio não fui motivada, muito pelo contrário, os professores não entenderam o porquê dessa profissão. Então iniciei a faculdade de Psicologia e comecei a trabalhar em uma escola, foi nesse momento que decidi seguir meu sonho (ser pedagoga). (DISCENTE 14, ago 2019).

Admiração e grandes mulheres que me educaram, amor por criança e ensino. Sempre gostei da escola e desde pequena brincava de ser professora. (DISCENTE 16, ago 2019).

O que me motivou a fazer o curso de Pedagogia ocorreu na minha infância. A professora do $1^{\circ}$ ano era incrível. Isso me motivou a ser professora, pois ela ensinava a turma com muito carinho e dedicação. Fiz o curso de magistério e comecei a trabalhar na área. também foi um motivo pela escolha. (DISCENTE 18, ago 2019).

O primeiro contato com as atividades e as dificuldades da minha irmã quando ela ingressou no fundamental 1, motivou-me a escolher Pedagogia. (DISCENTE 24, ago 2019).

Comecei a cuidar de crianças em casa. Sempre quis ser professora. Quando brincava com amigos de "escolinha" eu era sempre a professora. Isso me motivou a escolher a Pedagogia. (DISCENTE 29, ago 2019).

Quando estava no Ensino Médio pensava em cursar Psicologia, mas como o curso era caro para mim, optei por cursar Pedagogia. Sabendo que havia a matéria de Psicologia pensei: "vou começar a entender as crianças e depois compreendo os adultos." Mas quando iniciei o curso me apaixonei pela Pedagogia, principalmente quando comecei a trabalhar em uma escola. Hoje, já não penso em cursar Psicologia, mas me especializar na área da educação. (DISCENTE 30, ago 2019.)

A segunda pergunta do questionário diz respeito às lembranças de professores que contribuíram significativamente para a escolha do curso. A maioria das alunas alegaram que houveram professores que marcaram positivamente a vidas delas motivando-as, mesmo que indiretamente, a trabalhar na área da educação. Conforme as representações das discentes logo abaixo, pode-se identificar um único perfil 
profissional em que os professores foram afetuosos, atenciosos, bem-humorados e que buscaram inovar suas aulas com métodos novos para cativar seus alunos.

Sim, minha professora da pré-escola sempre me marcou, pois ela me mostrou a imagem de ser uma professora autônoma, sempre buscava métodos novos para que os alunos se interessassem e suas aulas. (DISCENTE 2, ago 2019).

Gostava da professora Ditinha que me segurava pela mão. Mas penso que foi na afetividade que ela me marcou. (DISCENTE 3, ago 2019).

Quando criança e adolescente tive duas professoras que me marcaram positivamente, a senhoras Fátima e Maria Silvia. As duas sempre acreditaram em mim e buscaram extrair aquilo de melhor que havia dentro de mim e isso me motivou e instigou. (DISCENTE 5, ago 2019).

Há três professoras que contribuíram para a minha escolha, duas do Ensino Médio e uma de um curso técnico. Ambas desenvolveram um excelente trabalho e sala com dedicação, esforço, atenção, preocupação, conhecimento, amor, dentre outros aspectos. Auxiliaram todos os alunos desde os que tinham mais dificuldades aos que tinham mais facilidades. (DISCENTE 6, ago 2019).

Sim, principalmente na Educação Infantil e Ensino Fundamental. No parque as professoras Patrícia e Vânia foram excelentes no estímulo para o interesse em aprender, além de todo carinho. Já nos anos iniciais do Fundamental, Maria Vita e Valdivina foram referências ao apresentar um mundo novo regado a muito aprendizado, descobertas, bom humor, carinho e demonstração de amor pelo que fazemos. (DISCENTE 11, ago 2019).

Tive uma professora de matemática que sempre inovou em suas aulas, era bem divertido e nós, crianças da época, adorávamos. Aquela energia e leveza da aula nunca saiu da minha memória. (DISCENTE 9, ago 2019).

Tive uma professora no Fundamental 1 que eu admirava bastante. Era doce, empenhada e firme com seus alunos. Despertava o interesse e conseguia lidar com as situações em sala. (DISCENTE 24, ago 2019).

Na $5^{\text {a }}$ série tinha uma professora que me ajudava em várias questões fora do conteúdo escolar, assim, tive maior confiança nela. Desse modo, identifiquei-me com seu trabalho. Assim também foi em um curso técnico que realizei após o Ensino Médio, identificando-me e espelhando-me em alguns professores. (DISCENTE 25, ago 2019). 
Excepcionalmente uma discente alegou que seus professores contribuíram negativamente para escolha do curso e por isso decidiu cursar Pedagogia para fazer a diferença na educação. Com base nesse comentário, pode-se identificar que o fato de o indivíduo estar atuando na educação como professor não significa que ele está sendo um excelente profissional. Sua identidade pode ser de um profissional capacitado em relação aos conteúdos disciplinares, mas a forma como expressa-se em suas aulas ministrando esses conteúdos pode motivar ou não seu aluno ao aprendizado. Dependendo da identidade desse professor, ele poderá impactar positiva ou negativamente a memória escolar de seus alunos.

A terceira pergunta do questionário remete-se ao o que o curso agregou à vida pessoal e profissional ao longo dos oito semestres. A maioria delas manteve a mesma linha de raciocínio alegando que, profissionalmente, o curso as fez compreenderem que cada criança tem sua singularidade e que ser professor é muito mais do que ensinar conteúdos, é atribuir valores em suas aulas e dedicar-se completamente pelo aprendizado de seus alunos. Em relação à vida pessoal, o curso contribuiu para a construção de valores como o respeito ao próximo, empatia, compreensão, resiliência e perseverança.

Em minha vida pessoal, a Pedagogia me transformou em um ser mais empático e compreensivo. Fez-me enxergar com olhos mais cuidadosos. Sempre digo aos meus amigos: "Se tiverem oportunidade, façam a Pedagogia. É um curso para a vida." E é assim que me sinto, mais pronta para a vida num todo. Quanto a minha vida profissional, acredito que me encontrei. Conforme fui fazendo o curso, todas as minhas dúvidas foram sumindo e hoje eu sei o que significa quando dizem: "Quem trabalha com o que ama, não trabalha." Eu amo o que faço. (DISCENTE 12, ago 2019).

Ao longo do curso de Pedagogia, pude amadurecer muito, tanto pessoal como profissional. Tive a sorte de trabalhar com professores excelentes que servem de inspiração, pois realizam atividades maravilhosas e compartilham seu conhecimento. Foi por meio do curso que tive a oportunidade de adquirir conhecimentos, didática, métodos de aprendizado para que eu possa poder exercer minha profissão. (DISCENTE 26, ago 2019).

Para minha vida profissional, agregou metodologias que poderei usar ao longo da minha carreira, capacitação para planejar e dar aula, falar em público e escrever textos acadêmicos. Para minha vida pessoal, agregou 
a importância de trabalhar em equipe, o respeito às diferenças do próximo, a importância de ser maduro e responsável em relações sociais. (DISCENTE 30, ago 2019).

A última pergunta do questionário diz respeito ao tema deste artigo, ou seja, o processo de construção da identidade do professor pedagogo. Dessa forma, as discentes manifestaram quais fatores acreditam ser fundamentais para a construção dessa identidade. Com base nos apontamentos das discentes, pode-se identificar três aspectos fundamentais para a construção da identidade do professor pedagogo: a formação, as experiências e os valores. A formação diz respeito a trajetória acadêmica do professor enquanto aluno na graduação, pois é o momento em que começa a adquirir competências e conhecimentos específicos por meio dos componentes curriculares, cursos de extensão e palestras sobre educação. As experiências remetem-se às atividades práticas por meio do estágio em que poderá exercer a criatividade, a responsabilidade, a busca por novas metodologias e a troca de experiências com os colegas. Por fim, os valores dizem respeito a forma como o professor atuará em sua profissão. Assim sendo, será importante ter amor pelo que faz, empatia pelo próximo, dedicação e se esforçar para ser um bom exemplo de ser humano e profissional.

Com base nas representações das discentes, pode-se afirmar que o processo de construção da identidade do professor pedagogo, de fato, inicia-se antes mesmo do ingresso na profissão, pois antes de ingressarem no Ensino Superior, as futuras pedagogas tiveram experiências fundamentais que sucederam a escolha do curso. Em suma, a influência de bons professores é primordial para essa escolha, pois esses professores, por meio de sua identidade, instigaram suas alunas a seguirem o mesmo caminho. Portanto, além de um profissional capacitado e inovador, o professor pedagogo deve ser uma pessoa acolhedora e a sua didática poderá ser baseada na afetividade.

\section{CONSIDERAÇÕES FINAIS}

A carreira docente estabelece a construção e a reconstrução de saberes que articulam dimensões pessoais, acadêmicas e profissionais. Além disso, implica a construção de 
valores e princípios edificados ao longo da vida que propõe ao profissional a reflexão sobre as ações desenvolvidas ao longo de sua formação. Assim sendo, o professor desenvolve competências e novas aprendizagens, assim, assume novas formas de ser e estar na vida e na docência.

Dessa forma, ser um professor pedagogo vai muito além do que a mera decodificação de métodos pedagógicos ou a formação acadêmica. Trata-se de um processo gradual sobre a construção de uma identidade profissional que inicia antes mesmo do ingresso no Ensino Superior, mas na trajetória de vida pessoal e profissional. Dessa forma, as representações da docência são manifestadas na entrada formal no ensino básico, nas relações familiares, sociais e históricas e no percurso profissional, independentemente da escolha docente ou não. Assim, aos poucos, o professor pedagogo vai se constituindo e se transformando na forma de ser como pessoa e posteriormente como profissional.

Levando em consideração a vida como um espaço e um tempo de formação, observase que o professor pedagogo traz em sua "bagagem profissional" referências sobre a docência que se concentram nas dimensões sociais presentes em seu percurso. Dessa forma, o contexto das relações sociais, históricas, o núcleo familiar e a dimensão acadêmica institucional marcam forte presença em suas primeiras experiências no âmbito da docência o que levam ao caminho da reconstrução de saberes, da sua profissionalização e principalmente da construção de sua identidade.

Portanto, o pedagogo torna-se professor a partir do momento em que descobre que sua identidade profissional depende primeiramente da sua visão de mundo e sua forma de ser e agir nele. Dessa forma, é importante que, antes de ser um bom profissional, seja um ser social que considera suas experiências de vida como um aprendizado contínuo, que agregue valores independentemente do ambiente social em que estiver e que tenha respeito por si mesmo e pelo próximo. 


\section{REFERÊNCIAS}

ALTET, Marguerite; CHARLIER, Évelyne; PAQUAY, Léopold; PERRENOUD, Philippe (Org.). Formando Professores Profissionais. Quais estratégias? Quais competências?; tradução Fátima Murad e Eunice Gruman - $2^{2}$ edição. rev - Editora Artmed, Porto Alegre, 2001.

BRAGANÇA, Inês Ferreira de Souza; Histórias de vida e formação de professores: diálogos entre Brasil e Portugal. Editora EdUERJ, Rio de Janeiro, 2012.

BRASIL. Conselho Nacional de Educação Conselho Pleno; Ministério da Educação. 2006. Disponível em: <http://portal.mec.gov.br/cne/arquivos/pdf/pces223_06.pdf> Acesso em: 01 jul 2019.

BRASIL. Lei de Diretrizes e Base da Educação no 9.394/96. Câmara dos Deputados. Disponível em: <https://www2.camara.leg.br/legin/fed/lei/1996/lei-9394-20-dezembro1996-362578-publicacaooriginal-1-pl.html> Acesso em: 03 jul 2019.

CONCEITO. DE; Conceito de Dimensão. 2014. Disponível em: <https://conceito.de/dimensao> Acesso em: 02 jul 2019.

GONÇALVES, Luciana dos Santos et al. O curso de pedagogia e o processo de construção da identidade do pedagogo. 2010. Disponível em: $<$ http://www.bibliotecadigital.puc-campinas.edu.br/tde_arquivos/3/TDE-2010-0309T064323Z 1578/Publico/Luciana\%20dos\%20Santos\%20Goncalves.pdf> Acesso em 03 jul 2019.

MARCELO, Carlos. O professor iniciante, a prática pedagógica e o sentido da experiência. Formação Docente-Revista Brasileira de Pesquisa sobre Formação de Professores, v. 2, n. 3, p. 11-49, 2010. Disponível em: https://revformacaodocente.com.br/index.php/rbpfp/article/view/17 Acesso em: 05 jul 2019. 
PIMENTA, Selma Garrido; LIMA, Maria Socorro Lucena. Estágio e Docência. $7^{\mathrm{a}}$ edição, editora Cortez, São Paulo-SP, 2012. (Coleção Docência em Formação - Série Saberes Pedagógicos)

\section{APÊNDICE - REFERÊNCIAS DE NOTA DE RODAPÉ}

3. BRASIL. Conselho Nacional de Educação Conselho Pleno; Ministério da Educação. 2006. Disponível em: <http://portal.mec.gov.br/cne/arquivos/pdf/pces223_06.pdf> Acesso em: 01 jul 2019.

4. BRASIL, 1996. LDB no 9.394, art. 82. Os sistemas de ensino estabelecerão as normas para realização dos estágios dos alunos regularmente matriculados no ensino médio ou superior em sua jurisdição. Disponível em: <https://www2.camara.leg.br/legin/fed/lei/1996/lei-9394-20-dezembro-1996-362578publicacaooriginal-1-pl.html> Acesso em: 03 jul 2019.

Enviado: Maio, 2020.

Aprovado: Agosto, 2020. 